Discursive Psychology: Implications for Counseling Psychology 


\begin{abstract}
In this article, we present discursive psychology (DP), a qualitative approach that focuses on the study of conversational and textual materials, including everyday interactions. Although DP is well-established methodologically and theoretically and used widely in Europe and in the Commonwealth countries, it is relatively unknown in counseling psychology in the United States. As such, the purpose of this article is to provide a general overview of DP and offer guidance for researchers who may be interested in studying and using DP. We thus discuss practical considerations for doing DP, including the development of research questions, carrying out data collection, and conducting DP-informed analysis. We also provide a general overview of the history of DP and key resources for those interested in studying it further, while noting the usefulness of DP for counseling psychology.
\end{abstract}

Keywords: conversation analysis, counseling psychology, discursive psychology, qualitative research 


\section{Discursive Psychology: Implications for Counseling Psychology}

Imagine a counseling psychology researcher is interested in therapists' and clients' conversations about their respective racial differences or similarities, a topic receiving increased attention in the multicultural counseling literature (Hays, 2016). For example, a therapist might use the skill known as immediacy (Hill, 2014) to initiate a discussion of race with a client from a different ethnic background (e.g., "You've talked about your mistrust of White people at work. I wonder what it's like for you to work with me, a White therapist?"). How would a researcher study this? A typical quantitative study might involve inviting clients from different racial backgrounds to complete a survey on whether their therapists initiated discussions of their racial differences or similarities, with levels of satisfaction being rated. Such a researcher might hypothesize that these satisfaction ratings may be positively associated with the therapeutic alliance, which might be moderated by clients' racial identities. Alternatively, a qualitative counseling psychology researcher might interview therapists about when they initiate therapeutic discussions about racial differences, their motives for doing so, and their perceptions of clients' responses to these discussions. Although both methodological approaches have merits, one important drawback is that neither involves an analysis of naturalistic psychotherapy data that represents what therapists and clients actually talk about and what is accomplished through their interactions.

In this article, we present discursive psychology (DP; Edwards \& Potter, 1992), a qualitative approach that addresses the aforementioned limitations by focusing on what people accomplish socially through the use of naturally occurring conversational and textual data. Although DP is a well-established methodological, theoretical, and analytical perspective, particularly in Europe and the Commonwealth countries, it remains relatively unknown in 
counseling psychology in the United States. The purpose of this article is to offer a general overview of DP and provide guidance for researchers who may want to study DP further. Specifically, we discuss the practical aspects of doing DP, such as developing research questions, collecting appropriate data, and engaging in analytic practices. Given that DP is generally thought of as a form of discourse analysis, we first offer an overview of discourse analysis. We then define DP and provide an abbreviated history of its development and scope.

\section{Overview of Discourse Analysis}

Within the field of qualitative research, discourse analysis encompasses a broad range of approaches to the study of language (Wetherell, 2001). It is helpful to conceptualize discourse analysis as an umbrella term that includes a variety of perspectives, all of which bring certain theoretical, methodological, and analytic assumptions. From critical discourse analysis (van Dijk, 1993) to Foucauldian discourse analysis (Arribas-Ayloon \& Walkerdine, 2008), to conversation analysis (Sacks, 1992), to DP (Potter \& Edwards, 1993) among others, discourse analytic approaches indeed vary widely but are collectively characterized as the study of talk and text as used in social practice (Potter, 1997).

Unlike many qualitative approaches, discourse analysis approaches share a common perception that language is not only descriptive and representative, but also performative; that is, discourse is assumed to be constructive of social life, as people do things with and through language. For instance, consider the following interchange:

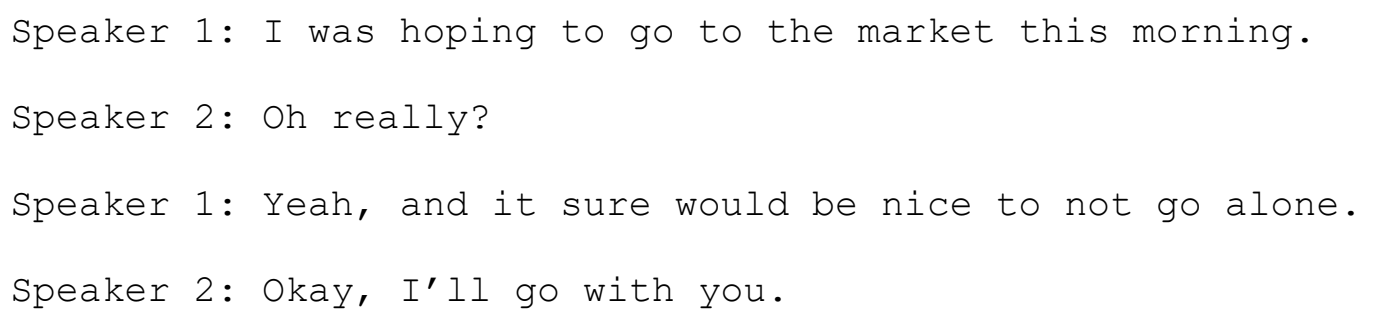


Here, Speaker 1's talk is heard as 'doing' an invitation, which is made evident with Speaker 2's response, "Okay, I'll go with you." In this instance, no direct invitation is given, such as "Would you come along?" Rather, Speaker 1 formulates an implicit invitation. Whether one is giving an invitation, blaming, seeking advice, complaining, negotiating, making a case, etc., such social activities often occur through language, and these very social activities are the site of study when conducting a discourse analysis. That is, language 'performs' or 'does' social life. It is not simply a neutral reflection of social life; rather, it is through language that things (like invitations, excuses, or even racial identity) are accomplished. Notably, this notion provides an interesting contrast to Pennebaker and colleagues' research on the positive social effects of engaging in the expression of language through writing (e.g., Slatcher \& Pennebaker, 2006). The idea that language is performative focuses more on what is socially accomplished through language (e.g., blaming), rather than on the effects of expressing oneself through language.

Theoretically, DP differs from other qualitative approaches that take the position that what is being said by speakers is a reflection of what they believe and think. For example, researchers using grounded theory or phenomenology often interview participants to try to understand what people actually believe. Alternatively, discourse analytic approaches are more concerned with social interaction and the performative nature of talk, and therefore do not take the position that the analyst can tease out the participants' true thoughts and beliefs by listening to the content of the interview. Instead, what speakers say is treated as a version of events, which is constructed in their narrative to portray themselves and others in a particular light. The view of language as performing a social action through its very construction (e.g., word choices) is not new, as it can be traced back to linguistics philosophers including Wittgenstein (1958) and Winch (1967). For example, a simple statement such as "The china dog I ordered online was 
broken when it arrived" could be heard as a statement of fact or it could be heard as a complaint. In this instance, if the recipient responded by saying "I'm sorry" this would be evidence that the original statement was treated as a complaint.

Notably, it was not until the 1980s that a proliferation of discourse analytic approaches occurred across multiple disciplines, including psychology. Perhaps unsurprisingly, each approach brings with it specific views on the definition of discourse, as well as the focus of analysis. Some forms of discourse analysis take a more fine-grained approach to analysis, whereas others attend to broader cultural, social, and institutional concerns (Avdi \& Georgaca, 2007). For example, critical forms of discourse analysis, such as critical discourse analysis, Foucauldian discourse analysis, and critical discursive psychology are positioned more as macroapproaches that address issues such as cultural identity, power, ideology, and oppression. Yet, where does DP fit within the broad umbrella, and what are its unique contributions to psychology, more broadly, and to counseling psychology, more specifically? DP is a microapproach that does not pre-assume social inequality, but rather examines the ways in which speakers interact through talk and whether they elect to make ideology, oppression, and inequality relevant in their social interaction.

\section{Defining Discursive Psychology}

DP is an approach grounded epistemologically in social constructionism, which seeks to revisit classic psychological issues. DP was developed in the 1980s and 1990s at Loughborough University in the United Kingdom by social psychologists interested in the study of psychological concepts through language (Edwards \& Potter, 1992). These scholars were dissatisfied with the traditional, cognitive ways of making sense of psychological processes. In response to the dominant cognitive view, DP offered a social constructionist perspective that 
foregrounded the study of discourse to understand psychological constructs and processes. The discipline of psychology has traditionally sought to explain mental health in terms of properties of individuals and has advocated a need for internal change and cure. In contrast, social constructionist work has sought to reframe psychological constructs (e.g., memory, personality, psychopathology), as being constructed socially (Burr, 1999).

Drawing upon social constructionism, DP's progenitors, Edwards and Potter (1992), argued that it is entirely appropriate to examine discourse in its own right rather than attempt to use discourse as a vehicle to access underlying mental processes. As such, DP was proposed as an approach rather than simply a method (e.g., a series of analytic steps). In other words, DP was devised as a way of thinking or theorizing about psychological concepts rather than simply representing a specific method for collecting and analyzing data (Potter, 2012). Furthermore, DP challenges the assumptions of traditional cognitive psychological theory in which cognition is treated as a representation of a mental state (Lester, 2011; Wooffitt, 2005). For a DP researcher, what people say is always situated, occasioned, and rhetorically formulated and, as noted, words are not understood as a reflection of what people 'really think' (Edwards \& Potter, 1992). In other words, it is assumed that what someone says does not necessarily connect to mental schema or their 'true' thoughts.

This approach was driven by three core aims, as outlined by Wetherell (2007). First, DP sought to study psychological topics with an explicit focus on language, including rules, emotions, representations, social categories, attribution, ideology, memory, gender, and identity. For example, rather than viewing identities as fixed cognitive states, DP researchers argued to treat them as flexible and changeable constructs created between individuals during conversations. Second, discursive psychologists sought to promote interest in new ways of 
theorizing and studying psychological constructs (e.g., memory, cognition, emotion) as made evident in text and talk. For instance, rather than text and talk being viewed as mere windows into people's cognitions, they were understood as ways of performing social actions. Thus, research in this tradition "starts with discourse not because of an interest in the psychology of language per se but because discourse is the fundamental medium for human action" (Potter, 2012, p. 4). Third, many of the early progenitors of DP sought to advance qualitative research methods, not just in the field of psychology but across the social sciences (e.g., Edwards \& Potter, 1992). For example, DP provided a critique of traditional quantitative and qualitative methods of data collection by promoting techniques for examining social interaction, which we discuss later in this article.

\section{The Three Strands of Discursive Psychology}

Historically, there have been different ways that DP has been pursued, resulting in multiple research foci. Potter (2012) noted that three main strands of discursive work have emerged during the last three decades. First, some of the earliest DP work focused on identifying 'interpretative repertoires' (i.e., groups of terms and categories that are built in talk in relation to a metaphor), most often within the context of interview data or group discussions. Wetherell and Potter's (1992) work around race and racism is one key example of this strand of DP, in which the researchers noted how participants in their study used groups of terms and categories to talk about race and racism. Work within this strand of DP has often taken up a critical perspective, attending to larger socio-political problems and concerns (e.g., Reynolds, 2013). Notably, for DP researchers interested in the study of power and cultural identity, this particular strand of DP offers useful theoretical and methodological insights.

Second, from the early 1990s onward there was a shift to studying naturalistic 
interactions such as everyday conversations or news interviews. Within the second strand of DP, researchers focused on the study of psychological matters as "objects in and for interactions" (Potter, 2005, p. 789). Drawing explicitly upon social constructionism (Berger \& Luckmann, 1967; Potter \& Hepburn, 2008), research within this strand of DP has served to respecify psychological constructs (e.g., cognition) as produced in and through interaction. Further, it was during the early 1990s that the term 'discursive psychology' was first used and positioned as a distinct discourse analytic approach (Edwards \& Potter, 1992).

Third, from the mid-1990s onward, DP began to be influenced by conversation analysis, a qualitative methodology that analyzes the details (e.g., pauses, rising and falling intonation) and the sequential order of talk (e.g., conversational turns). Potter (2012) noted that DP's engagement with conversation analysis has resulted in DP researchers most often collecting naturally occurring data and completing an analysis that attends to microfeatures of the discourse (e.g., pauses, prosody, embodied interactions). Indeed, contemporary DP is often reflective of the influence of conversation analysis, resulting in a close analysis of the discourse with attention to the sequential nature of interaction.

\section{Differences Between DP and Other Qualitative Approaches}

To provide a snapshot of recent qualitative counseling psychology research, we reviewed every qualitative study published in the Journal of Counseling Psychology and The Counseling Psychologist over the past 5 years, from 2012 through 2016. We identified 67 qualitative studies in which consensual qualitative research $(n=22,33 \%$; Hill, Thompson, \& Williams, 1997) and grounded theory ( $n=14,21 \%$; Strauss \& Corbin, 1998) were the most common qualitative methods used. When compared to these and other qualitative approaches to research, contemporary DP differs in (at least) three ways. 
First, conceptually, DP strongly emphasizes the performative nature of language. This emphasis informs how a DP researcher engages with data. For example, in reading the transcript of a therapist and client talking about racial differences, a DP researcher will focus more on what the therapist and client are socially accomplishing through their talk (e.g., is she defending or justifying her perspective on race?). To provide another illustration, suppose a researcher interviews a therapist about what she does to establish a therapeutic alliance with clients from diverse backgrounds. From a DP standpoint, such interview data reveals less about the process of establishing a therapeutic alliance with a client and more about what the interviewer and therapist are trying to accomplish socially through the interview. For instance, such data might demonstrate a therapist's attempts to communicate her credentials as a culturally competent practitioner to the interviewer. An advantage of using DP therefore is that it focuses on the interactions between the psychologist and the client, rather than on the interviewer and the psychologist.

Second, contemporary DP places great emphasis on the utility of naturally occurring data rather than interview or focus group data (e.g., actual therapy conversations vs. conversations about the therapy). As such, there is an explicit focus on therapy recordings that reveal what a therapist and client actually do when engaged in a therapy session. Thus, an advantage of DP is that by analyzing data from a naturally occurring therapy session, a spotlight is placed on realworld practice.

Third, compared to other qualitative approaches, there are differences in the method of analysis. DP is distinct in its emphasis on a fine-grained analysis of talk, including an emphasis on the prosodic (e.g., pitch, loudness), sequential (e.g., conversational turns), and where possible, 
paralinguistic (e.g., facial expressions) nature of conversations. An advantage of this approach, therefore, is its focus on the ways in which things are said, not simply on what is said.

\section{DP's Relevance to Counseling Psychology}

Although DP is currently underutilized in counseling psychology, we argue that it is a natural fit for the field for several reasons. First, DP's emphasis on naturally occurring data is consistent with the clinical training of most counseling psychologists. Counseling psychology students often receive psychotherapy training that includes the use of video recordings of therapy sessions, verbatim transcriptions of therapy (or therapy role play) sessions, and observing nonverbal features of talk, such as tone of voice and the use of silence (Hill, 2014); these are quintessential features of DP.

Second, counseling psychologists who embrace social constructionist approaches to therapy, such as solution-focused therapy (DeJong \& Berg, 2013), narrative therapy (Combs \& Freedman, 2012), and strength-centered therapy (Wong, 2006) will likely be familiar with DP's epistemological foundation, which emphasizes the performative nature of language and the social construction of reality. From a social constructionist standpoint, the language that therapists and clients use is conceptualized not just as representations of their emotions and cognitions but as social tools to construct versions of reality (Anderson, 1997). Accordingly, it is likely not difficult for counseling psychologists who embrace this standpoint to extend this understanding beyond psychotherapy to all forms of discourse, including everyday talk, email conversations, and social media.

Additionally, to some extent DP may also appeal to those taking a social constructivist position in their therapeutic work. There is some overlap between social constructionism (i.e., a broad assembly of approaches that emphasizes that human experience and perceptions are not 
fixed but mediated linguistically, historically, and culturally) and social constructivism (i.e., an orientation that relates to social constructionism but places greater emphasis on cognition rather than language), as both positions argue that structures and events cannot be captured objectively (Franklin, 1998). Yet, it can be more challenging for a cognitively oriented constructivist practitioner to challenge her beliefs in inner psychological structures. Thus, there may be some tensions for constructivists adopting a DP position, as they may need to suspend, at least in part, their ideologies about the presence of inner mental states and reposition these as socially constructed through social interaction.

Third, DP research might help contribute to a revival of psychotherapy research within counseling psychology. A content analysis of research in the Journal of Counseling Psychology and The Counseling Psychologist revealed a precipitous decline in counseling-related articles from $78 \%$ in 1978 to $37 \%$ in 2008 (Scheel et al., 2011). Counseling psychologists' access to naturally occurring psychotherapy data (because of the common practice of video recording trainees' therapy sessions) might reduce the logistical burden of conducting psychotherapy research.

Fourth, DP can also help bridge the gap between science and practice, a topic of longstanding interest in counseling psychology (Ridley \& Laird, 2015). Indeed, in contexts of import within counseling psychology, discourse analytic approaches such as DP can focus on the co-construction of a client's problems and how solutions are shaped through interaction (Georgaca \& Avdi, 2009), with the potential to also inform and positively change practice (Stokoe, 2014). More specifically, DP can provide new opportunities for counseling psychology researchers to collaborate with practitioners on improving the quality of psychotherapy services (Kiyimba \& O’Reilly, 2016; O’Reilly \& Kiyimba, 2016). A key strength of DP research as 
applied to psychotherapy is its emphasis not just on what therapists do, but more importantly, on how they do it. For instance, researchers who have empirically identified the qualities of highly effective therapists (Hill et al., 2017; Wampold, 2015) can then use DP to showcase the work of a few highly effective practitioners by spotlighting the specific discursive practices they use to display these qualities in therapy. The findings from DP research can then be used as a training tool to highlight best practices (Stokoe, 2014). Indeed, many DP studies on psychotherapy and other clinical practices conclude with recommendations for practitioners drawn directly from analyses of practitioner-client interactions (e.g., Hepburn \& Jackson, 2009; Parker \& O’Reilly, 2012).

Finally, DP can expand the boundaries of counseling psychology research by addressing novel research questions in core areas of counseling psychology. DP researchers might do this by reconceptualizing psychological constructs such as emotions, racial identity, acculturation, and self-efficacy, as social accomplishments that are realized through discourse.

\section{General Research Questions Addressed by DP}

An overarching concern in developing appropriate research questions within DP has been a commitment to inductive inquiry, and valuing data-driven exploration of phenomena. This stands in stark contrast to a commitment to hypothetico-deductivism, whereby the research rests specifically on a precisely specified hypothesis in quantitative research (Potter, 1996). Although operating from a range of different epistemological positions, many approaches to qualitative research also rest on a specified research question, with a firm underlying principle that this guides the research process. Where the methodology warrants the development of a question as an inherent aspect of its process, this is both necessary and acceptable. Further, as Yin (2016) noted when describing qualitative research practices generally, it is common for qualitative 
researchers to conceive of their research questions in one of two ways: (a) as pre-defined and fixed, or (b) as emerging from the data collection process. In DP, there is a broad interest in understanding how social actions are achieved through talk, which generally becomes evident after data collection and analysis begin. In other words, the analysis process makes evident specific research questions. Thus, in DP research the act of designing a specified (and fixed) research question at the beginning of a project is not appropriate (Potter, 2012).

To clarify, the research questions emerge during the process of DP data analysis. Indeed, identifying a research topic is an important starting point, recognizing that the topic should be aligned with the assumptions of DP (Wiggins, 2017). Although qualitative research generally is iterative and inductive, the use of guiding, rather than specific research questions, result in a much more inductive process; that is, the data collection and analysis processes often serve to shape a research question. Generally speaking, those practicing DP aim to understand what happens in particular kinds of interactions, such as child therapy (Lester, 2014), family therapy (O’Reilly \& Parker, 2014;), paranormal accounts (Wooffitt, 1992), police interrogations (Edwards, 2006), law courts (Auburn et al., 2016), television interviews (Clayman, 2002), and so forth to gain an appreciation of what goes on in those settings. Thus, the underlying premise driving the research process is a bottom-up, inductive philosophy, with the "analytical gaze" focused "on people and interaction, not individuals or their mental processes" (Wiggins, 2017, p. 62). The DP approach allows for the data to reveal novel and important insights that were not necessarily theorized at the outset. Therefore, at the start of a study, it is essential that the focus of inquiry is open enough to allow for new insights to emerge during the data analysis process. For example, beginning questions may be: 
- How do the therapist and client co-construct a relationship problem in couple therapy?

- How do people use memory as a social resource when sharing about their past?

- How are the client's and other people's identities constructed in counseling? Although these overarching research questions may drive a project, it is often the case that familiarity with the data generates more specific research questions, such as: 'How do individuals in couple therapy account for their behavior?' Thus, a researcher engaged in a DP study should remain open to the possibility that the research question may become more specific as the study unfolds.

\section{Potential Counseling Psychology Research Questions that DP can Address}

In this section, we illustrate four types of research questions across a broad swath of counseling psychology topics that researchers can study using DP. First, suicide risk is a common concern that counseling psychology practitioners encounter in their clinical work with clients (Westefeld et al., 2000). Suicide assessment and intervention are particularly challenging areas of counseling psychology practice because they often require therapists to shift to a more active and investigative role. For example, therapists might persuade clients to remove access to lethal means and may also breach clients' confidentiality (Shea, 1999). Examples of DP research questions on this topic include: What discursive devices do highly skilled clinicians use to strike a balance between the investigative nature of a suicide risk assessment and the importance of expressing empathy and building rapport? What interactional practices do clinicians and clients use to collaborate on, negotiate, and/or resist a suicide risk reduction plan?

Second, in vocational psychology, researchers can use DP to study the interactional practices involved in career assessment. In career counseling, it is not uncommon for the 
counselor to administer and interpret the results of a career assessment tool (e.g., the Strong Interest Inventory; Herk \& Thompson, 2012) to a client and then discuss the relevance of these findings for the client's career decisions (Hansen, 2005). Researchers can use DP to explore how clients respond to their counselors' interpretation of career assessment results, particularly when these results are perceived by clients to be unexpected, as well as how counselors manage their clients' experience of surprise. Examples of DP research questions on this topic include: What interactional practices do counselors use when reporting unexpected career assessment results to clients? How do counselors manage and negotiate clients' surprise?

Third, research on race and racism are some of the most fertile areas of multicultural counseling psychology research (Quintana, Chew, \& Schell, 2012). Within counseling psychology, such research is typically conducted by administering Likert-type scales that measure these constructs and then examine their associations with other outcomes (e.g., Wong, Liu, \& Tsai, 2014). An alternative approach to studying these constructs is to focus on naturally occurring race talk, which involves dialogue in which race is the focus of conversations among people of different racial backgrounds (Sue, 2013). To illustrate, race talk could occur in a multicultural counseling class in which students engage in personally relevant discussions on race, racism, and racial privilege. Because interactions about race are potentially challenging conversations often characterized by defensiveness, anxiety, and emotional intensity (Sue, 2013), they provide fertile ground for a DP researcher. A DP study could examine how students from diverse racial backgrounds in a multicultural counseling class justify and resist their and other classmates' assertions on race, racism, and racial privilege. Examples of DP research questions on this topic include: How do students in a multicultural counseling classroom justify and defend 
their position on race? What discursive practices do multicultural counseling instructors use to manage disagreement in classroom discussions on race?

Fourth, the study of positive psychological interventions is an emerging area of research in counseling psychology (Magyar-Moe, Owens, \& Scheel, 2015). Some positive psychological interventions are highly interpersonal and interactional, and are therefore a natural fit for DP research. To illustrate, Seligman, Steen, Park, and Peterson (2005) found that writing and then personally reading a letter of gratitude to another person led to a short-term reduction in writers' depressive symptoms and an increase in their happiness. A DP study of this gratitude intervention might involve an analysis of individuals expressing gratitude to their benefactors, including the discursive devices through which such interpersonal gratitude is conveyed and received. An example of a DP research question on this topic includes: What conversational features are used when 'expressing gratitude' and how do they serve to convey 'gratitude'? Similarly, a DP study could analyze the conversational features used by a discloser and a listener during the process of capitalization, which involves the disclosure of positive personal information (e.g., a promotion at work) and a positive response to such disclosure within an interpersonal relationship (Conoley et al., 2015).

\section{Types of Data Used in DP Research}

To access people's actual social practices, many DP researchers prefer to work with naturally occurring data. Although some forms of DP research do rely upon interview data (see Wetherell \& Edley, 2014), over the years there has been a methodological shift towards naturally occurring data (Potter \& Hepburn, 2005). A core benefit of utilizing naturally occurring data for research in counseling psychology is that examining such conversations avoids decontextualizing the data (Sacks, 1987). 
Although there is some debate about what exactly constitutes naturally occurring data, it is generally understood to be data that would exist as a natural event if it were not recorded. Notably, there are some tensions among DP researchers regarding the degree to which data might be considered natural and how this might be determined. For example, some researchers have argued that the naturalness of data are "always relative to the analytic context in which it functions as data, so it is never an inherent property of the materials" (ten Have, 2002, p. 529). Additionally, criteria for determining naturalness include the methods used for collecting data and the degree of researcher involvement (Speer, 2002). This does not mean that data collection methods that have a greater degree of researcher involvement are any less valid; rather, it is important to acknowledge that data collection is always situated and therefore a researcher should be transparent about how the data were collected and conceptualized (Potter \& Hepburn, 2012). Thus, a researcher's agency is a key factor in determining the type of data; natural events would still occur even if the researcher were unable to record the event (Potter, 2002). For example, if a counseling psychologist scheduled a therapy session with a client and it was to be recorded for research, the therapeutic session would still occur regardless of whether it was recorded for research purposes or not. This is essentially what makes the data 'natural' as opposed to researcher-generated data, such as a qualitative interview.

Underlying this preference for naturally occurring data is DP's post or anticognitive position (Potter, 2002). In other words, there is a commitment to expose the limitations of the cognitive perspective and provide an alternative approach that considers the discursive actions within text and talk. Thus, contemporary DP rejects the notion that researcher-generated methods for collecting data are legitimate ways of accessing participants' real cognitions about phenomena (Potter \& Hepburn, 2005). Essentially, DP rejects the notion that it is possible to 
access what is inside an individual's mind, as if their attitudes, memories, or beliefs were static entities. Instead, DP researchers assume that people's attitudes, memories, or beliefs are interactionally accomplished through talk and/or text.

In DP, the difficulty with researcher-generated methods of data collection such as interviews is that the respondent is treated as a reporter on events, cognitions, and so forth, as if events and cognitions were tangible and accessible (Potter \& Hepburn, 2005). Furthermore, researcher-generated data are treated as retrospective accounts of events and experiences, which depending on the researcher's epistemological position may be viewed as biased by confounding factors, such as memory distortion or personal attributes of the researcher and participant.

\section{The Analytic Process of Doing DP Research}

As with any inductive approach to analyzing qualitative data, the insights that come from constant reengagement with the data are cumulative and multi-layered. Typically, in DP, analysis begins at the transcription stage with the researcher engaging with the data through repeated listening and viewing while transcribing. Frequently, very detailed transcripts are developed using the Jefferson approach (Jefferson, 2004), allowing the researcher to represent the microdetails of interactions, as illustrated in the extracts presented next and in Appendix A. For instance, square brackets represent overlapping speech and a downward arrow denotes a decreasing intonation. This transcription system is designed to capture as closely as possible, not just what is said by speakers, but how it is said, and thus includes features such as intonation,

pitch, volume, speed, and so forth as this is important for analysis. Notably, many DP researchers complete their own transcriptions, as this interpretative process is understood as an important means by which to gain familiarity with the data. 
DP researchers have recognized the need for explicating the process for implementing DP in practice through a series of procedural steps. And, whereas DP does not espouse a step-bystep procedure in the traditional sense, it is helpful to consider the overlapping stages involved in doing DP. In a comprehensive and accessible chapter, Potter (2012) presented seven stages, which we summarize in Figure 1 and then subsequently discuss. The numbers on the left of the figure refer to the steps, which should be understood as overlapping.

First, researchers must thoughtfully obtain data access and participant consent. Potter acknowledged that, for many, this is challenging due to the preference for naturally occurring audio and/or video-recorded data, which can make gaining access difficult.

Second, it is important to consider data collection carefully, particularly in that there are no hard rules about sampling or sample sizes. Although it can be useful to build a large interactional data set related to a specific phenomenon of interest, even a small amount of interactional material (e.g., 1-2 hr of talk) can be useful for DP. It is critical to recognize that in DP the sample size does not equal the number of participants; rather, sample size refers to the amount of interactional data. The sample is the discourse itself rather than the people producing it. In fact, sample sizes reported in published DP studies vary widely, with some including $6 \mathrm{hr}$ (e.g., Lester, Karim, \& O’Reilly, 2014) or less of interactional data, and others involving well over $100 \mathrm{hr}$ of interactional data (e.g., Lester, 2014). Depending upon the purpose and scope of a given research study, a range of sample sizes can be justifiable. Further, it is important to keep in mind that a DP researcher's data might be text-based (e.g., online discussion groups) or include images (e.g., video blogs). 
Third, a DP researcher must consider data management, which becomes increasingly important as the project evolves. Data management entails collating digital files, transcripts, and analytic notes in the process of generating a clear and transparent audit trail.

Fourth, a DP researcher engages in a detailed transcription process, which is an essential aspect of the analytic process. The transcripts and the recordings are in constant use throughout the analysis, with the level of the transcripts' detail shaping the interpretative process.

Fifth, a DP researcher engages in (re)developing research questions. As noted previously, unlike many other forms of research, research questions in DP evolve iteratively and are often more fully developed once the analysis process is well underway.

Sixth, analysis of the data is a central practice within a DP study, and perhaps the most crucial and time-consuming aspect of the research process. Within DP, analysis involves a systematic examination of the entire dataset to build a corpus of examples that can be analyzed carefully. The examples generally relate to the identified phenomenon of focus (e.g., how clients build a case that they are a supportive partner). Finally, a DP researcher must engage in evaluating the quality or validity of the study, which we discuss later.

More broadly, to facilitate the analytic process, DP researchers often participate in data sessions with others to collectively examine the detail of the data. By examining the data in conjunction with others, different perspectives and new ideas are generated. These data sessions are also ideal training platforms for novice DP researchers to learn alongside more experienced researchers. The kinds of questions that are typically examined within these group data sessions are: (a) What are the primary social actions being performed in and through the talk?, (b) What might be at stake for the participants?, and (c) How are psychological attributes, such as 
memory, used as social resources? One framework within DP that serves as a lens for analyzing interactional data is the iscursive action model (DAM).

\section{The DAM and Therapy}

DP researchers often employ what is referred to as the DAM, a framework that guides the analytic stage. This is not a model in the traditional sense; rather, it is more of a conceptual scheme that captures some features of participants' discursive practices (Edwards \& Potter, 1992). In their design of the DAM, Edwards and Potter emphasized three elements: (a) action, (b) fact and interest, and (c) accountability. Thus, these three elements can help the analyst make sense of the data. We consider each of these elements in turn.

The extracts used in this section of the paper are all taken from a therapy data corpus involving families, with the purpose of exploring how the process of therapy works in practice. This data corpus involved four families across a series of therapeutic sessions and two therapists, and included approximately $22 \mathrm{hr}$ of naturally occurring video-recorded therapy. We refer to families by pseudonyms throughout to protect anonymity.

\section{Action}

The first element concerns the action-oriented nature of practices. Talk is understood as performative in that when people communicate with one another they are doing something such as complementing, inviting, complaining, justifying, persuading, and so forth. More particularly, in contrast to cognitively-oriented models, the DAM conceptualizes psychological phenomena (e.g., memories, attributions), as social actions rather than as mental constructs. A DP researcher, rather than looking for themes in the data that represent what participants' attitudes are about the topic in question, takes a position of inquiring about the performative action that the language accomplishes in the social context of the interaction. For counseling psychologists, such an 
approach provides a mechanism for examining the data beyond the text and seeking to understand the subtext. Extract 1 is taken from the Clamp family, in which Mr. Clamp is seen to be complaining about social services to the family therapist (FT).

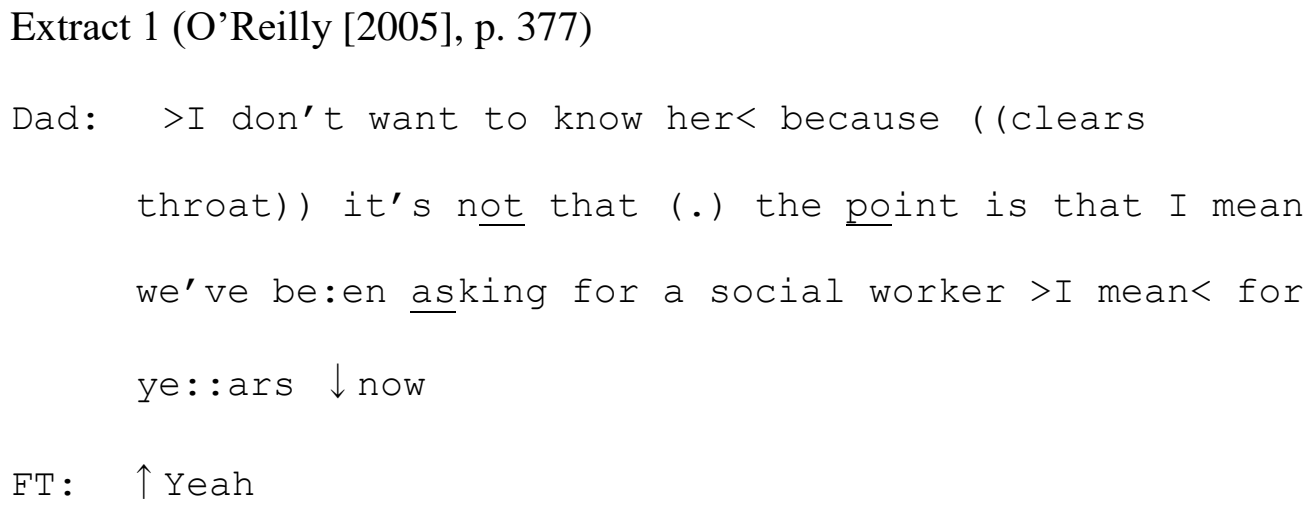

At this point in the session, Mr. Clamp (Dad) had revealed that there had been concerns raised about his parenting skills. The first part of the DAM is to look for social actions performed by speakers. The social action of doing a complaint is easily identifiable in this segment of talk, as Mr. Clamp constructed the current social worker in a negative way, stating "I don't want to know her," and assigned agency and moral fault with the organization: "we've been asking for a social worker for years now." Mr. Clamp was not just describing the actions of the social services agency, but presented what is hearable as a complaint about the agency's lack of action for a prolonged period of time. Further, the prosodic and paralinguistic features can have meaning. By stretching certain words (e.g., ye::ars), Mr. Clamp emphasized those particular words, which strengthened his complaint.

For the sake of pedagogy, we provide a short contrast here with more traditional qualitative methods that rely on developing coding frameworks. A foundational premise of DP is that words are not just used to describe things (either external experiences or internal processes), but are used to perform interactional action. In this case, a thematic analyst or grounded theorist, for example, may code the extract of data as "needing more help from social services" or "asking 
for help for a prolonged period," as that describes what is being said. However, DP takes into account not only the speaker but also the person who is listening and responding. By doing so, DP considers the interactional dynamic between speaker and listener and the socially recognizable action that is being performed through the description.

\section{Fact and Interest}

The second element is fact and interest, which broadly refers to how people present descriptions as factual to deal with or manage any potential (mis)understanding of them having a stake or interest in the outcome. The term stake is often used to refer to what might be in question or at risk for the speaker. This is not to be understood in the motivational sense; instead, it is important to examine how people treat each other as an entity with desires, motivations, and biases, which are displayed through their reports (Edwards \& Potter, 1992). In relation to stake specifically, individual stake is managed in interactions and carefully accomplished by implying that the speaker does not have a vested interest in the position that is espoused. Typically, speakers manage stake by presenting or assembling their report as factual. They achieve this through a multitude of discursive devices, such as extreme case formulations (e.g., "you are always doing that"; Pomerantz, 1986); three-part lists (e.g., "he was tall, dark and handsome; Jefferson, 1990), or systematic vagueness (e.g., "I think it was a couple of months ago, but I didn't really notice"; Edwards \& Potter, 1992).

Within the various settings in which counseling psychologists work, stake and interest are important concepts to bear in mind. Statements that are presented as disinterested factual reports may have embedded within them social actions that are rhetorically designed to manage how the speaker's motivations are perceived. For example, in Extract 2, Mr. Clamp inoculated against any forthcoming accusation of poor parenting. 
Extract 2 (O’Reilly \& Lester [2016], p. 500)

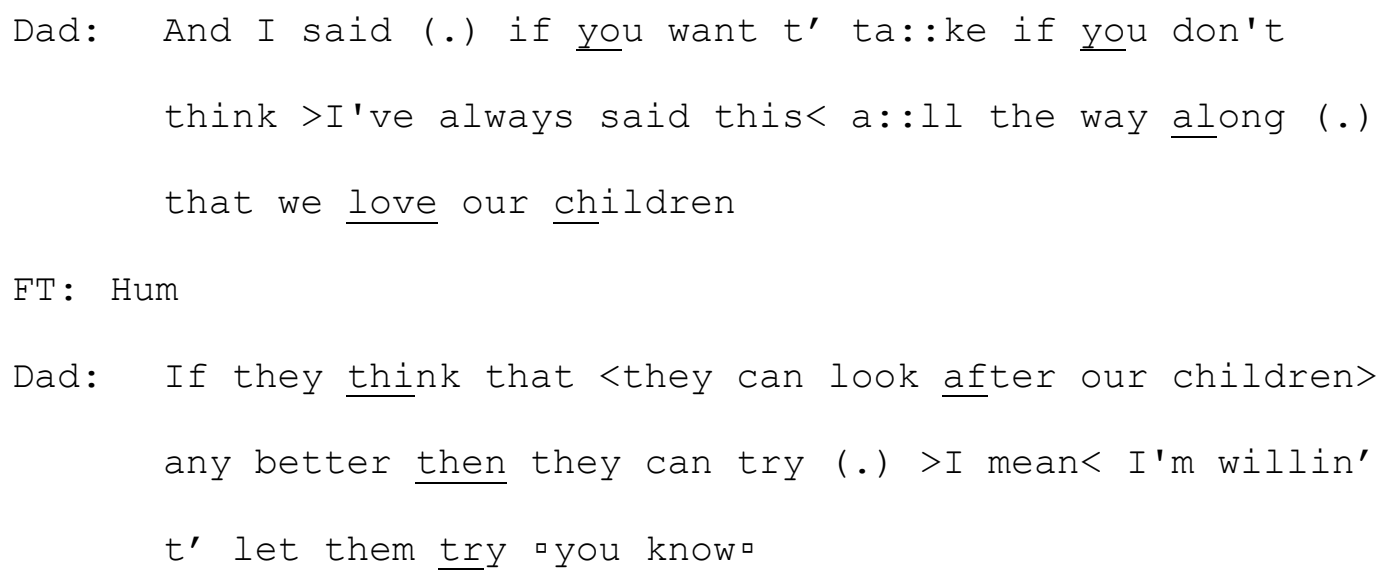

By reporting what the father said to the social worker at the time of the event, this account described the intention of the social service agency to remove the children from the family's home. However, the action being performed in this segment was rather complex; that is, the father has a vested interest (stake) in being viewed by the therapist as a good enough parent, and thus he inoculates against any potential inference that his parenting is not good enough. In this example, stake can be considered in the sense that there is potential for the therapist to view the parents as being at fault for creating a situation where the children might need to be removed from their home. Mr. Clamp managed his stake in this matter by presenting a good parent identity, reporting that he acted in the child's best interest.

\section{Accountability}

The final element is accountability. As Edwards and Potter (1992) noted, speakers routinely deal with issues of responsibility, agency, and blame when reporting events. The relationship between blame and accountability is that when the social action of blame is constructed, it immediately invokes the necessity for the blamed person to provide an account for their blameworthy action. For example, when someone is late, the person left waiting may request an account for the lateness, and the person who arrived late may blame the inadequate 
public transportation system. An aspect of the accountability element within the DAM is the notion of footing (Goffman, 1981). Footing relates to the way that speakers report events in such a way as to make attributions about the speaker and the audience. In other words, it is a form of positioning, which manages the actors' accountability in interactions.

The value of attending to accountability in interactions is that clinicians may be able to recognize the mechanisms by which clients account for their behaviors or blame others. For example, in Extract 3, Mr. Clamp repeated to the therapist the account that he had previously provided to the school regarding the presence of bruises on his eldest son. In this way, he also provided an account for his actions to the therapist in the current interaction.

Extract 3 (O’Reilly [2005], p. 376)

$$
\begin{aligned}
& \text { Dad: ... reached him to the scho:ol and they turned round } \\
& \text { and said there'll ( } 1.0) \text { be erm (.) the } \downarrow \text { bruises on } \\
& \text { Phillip and the reason why they were there .hh } \\
& \text { because I smacked his *bum for (1.0) being naught } \downarrow \text { y } \\
& \quad \downarrow \text { Yeah } \\
& \text { FT: } \quad \text { Then the social services come out and (.) > God knows } \\
& \text { Dad: what< (.) the police were o: ut and (.) everything (.) }
\end{aligned}
$$

Recognizable here is that Mr. Clamp presented a double account. In the first instance, he repeated the account that he provided to the school, which acknowledged that they might notice visible bruising on his son Phillip. He accounted that the reason for this was Phillip's own naughty behavior, which warranted a justifiable punishment of a "smacked... bum." In the current context of the therapy, this was presented as a normative form of discipline and the reiteration of the account provided to the school can also heard as designed for the therapist. 
What this achieves is a foundational premise for what is subsequently formulated as an overreaction, as he reported that the police and the social services agency were called for this.

The DAM thus provides a helpful structure for analyzing interactional data, as it offers an explicit framework for examining the potential social actions of the speakers and suggests the kinds of questions that the DP researcher may ask of the data. In seeking to understand the social actions of people, a DP researcher explores many possible discursive actions with the goal of understanding the world from the perspective of the speakers. We suggest that this analytic commitment is congruent with the tenets of counseling psychology, which advocate for prioritizing the client's viewpoint (Strawbridge \& Woolfe, 2010).

To this point, we have separated our examples to illustrate the three components of the DAM sequentially. However, when practicing DP it is often the case that the three components are integrated. To demonstrate this, we offer an example from the same therapeutic data set (but a different family) to illustrate how the three components of the DAM might be considered together.

Here, a male therapist and his client discuss the client's previous use of pornographic magazines and his wife's reaction.

Extract 4 (O’Reilly \& Parker [2012], p. 461)

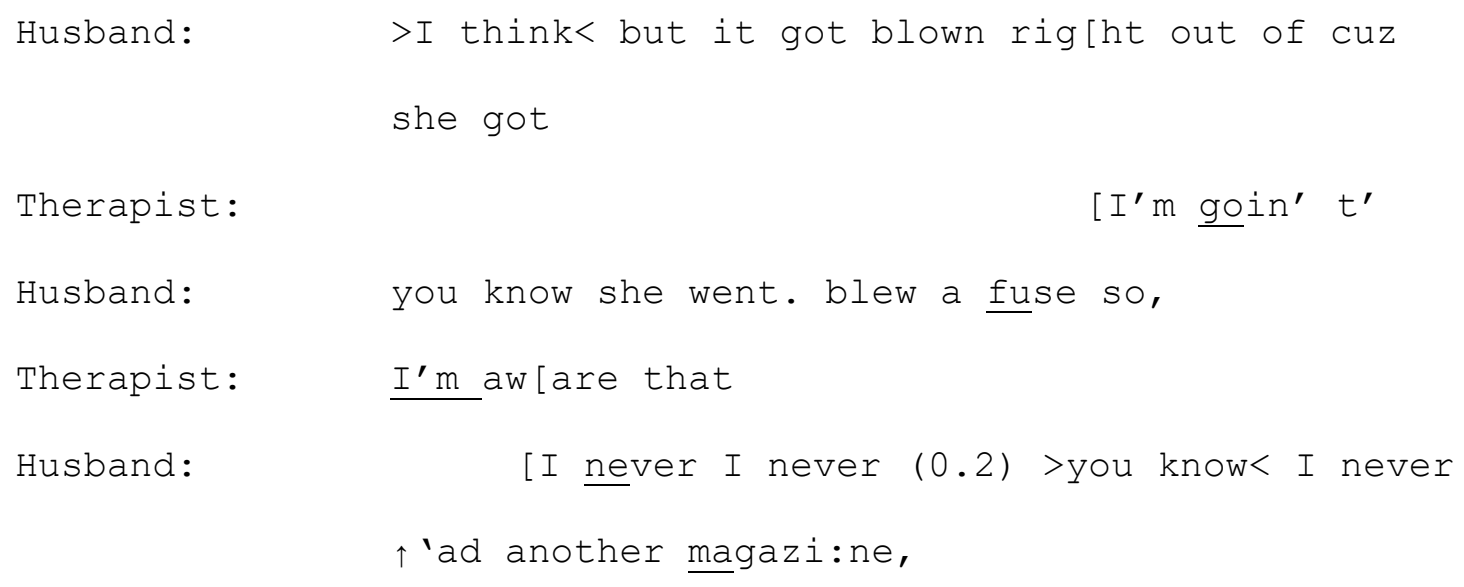




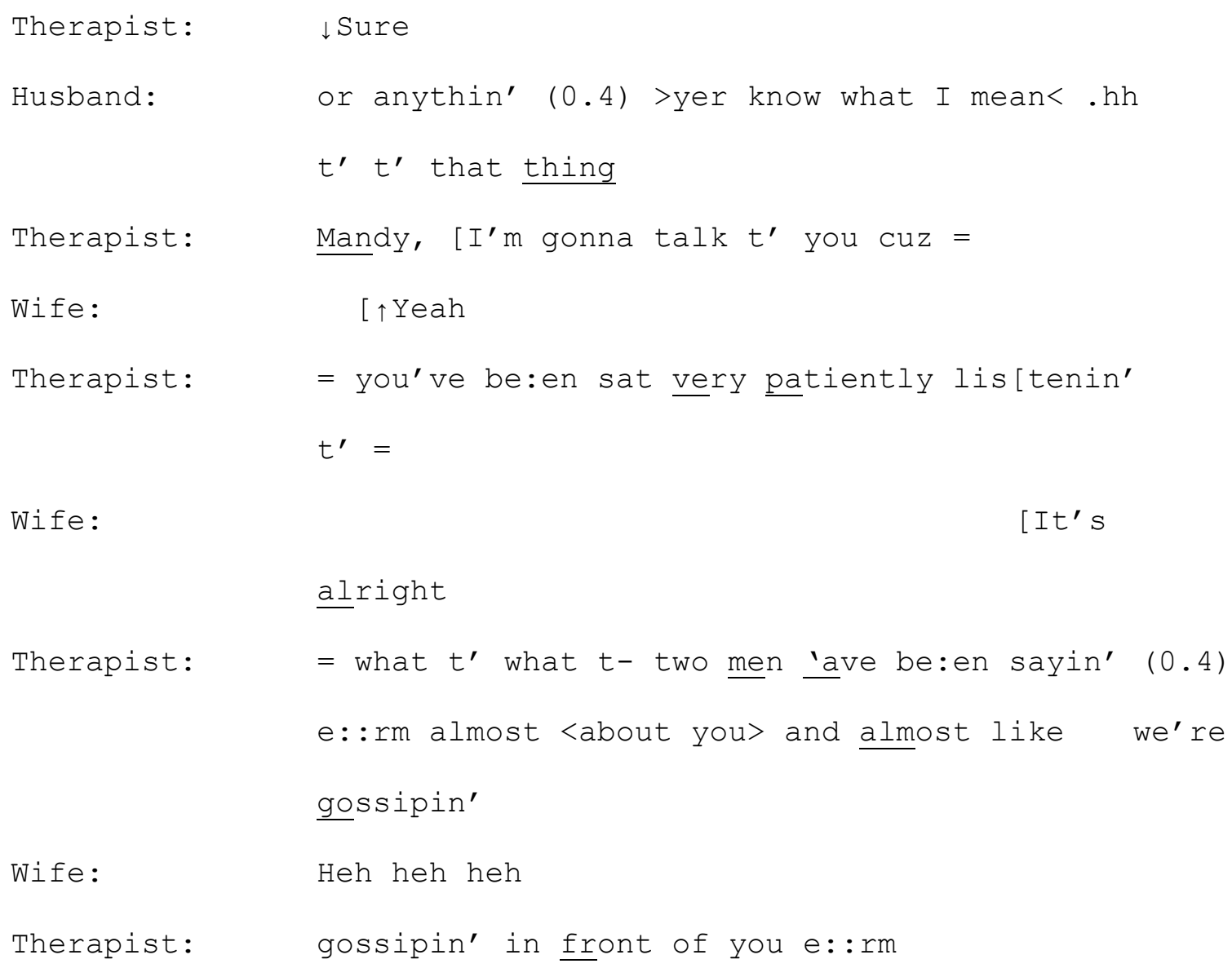

DAM is a useful framework for examining the interaction here. The first element, action, examines the social actions at play in the interaction. In beginning the analysis, a useful question to pose is: What social action is being performed? In Extract 4, the action performed by the husband is to minimize the problematic nature of his use of pornographic material. He does this in two main ways. First, he minimizes the problem by positioning his wife's response as an overreaction (she "blew a fuse") and second, he draws upon a repertoire of temporality by asserting that he no longer buys these magazines ("I never had another magazine"). The initial social action performed by the therapist is a demonstration of hearing the husband's version of events through an acknowledgement token "sure." The following social action is a deliberate inclusion of the wife in the interaction through an explicit invitation to join the conversation, with "I'm gonna talk to you." The therapist manages the potential for misalignment by 
acknowledging how she may construe the conversation between himself and the husband as a negative portrayal of "gossip" about her.

The second element, fact and interest, refers to the construction of descriptions as factual and manages the way that people present themselves in a positive light, while demonstrating no vested interest or stake in the outcome. In the extract, what is at stake for the husband is a possible interpretation that he has been engaging in the problematic use of pornographic material. The way that the husband manages his identity as a good husband is by showing that despite the wife's perceived overreaction to the material, he got rid of the magazine and did not bring any additional magazines into the house, stating: "I never had another magazine." For the therapist, what is at stake in this interaction is a possible misunderstanding by the wife that he has aligned with the husband, and he manages this directly by an effort to include the wife in the conversation and addressing her by name, stating: "Mandy, I'm gonna talk to you."

The third element, accountability, refers to the process of managing blame and responsibility in situ. In this example, the therapist treats the exclusion of the wife as problematic and something that he may be blamed for, and would potentially be accountable for, in his role as therapist. Furthermore, the therapist orients to the possibility of being held accountable for the way in which he and the husband have been discussing the wife in her presence. He does this explicitly by suggesting that she may feel that the two men have been gossiping about her (see Parker \& O’Reilly [2012] for a full discussion).

\section{Quality in DP Research}

Antaki et al. (2003) suggested that there are six important considerations for producing quality discourse research, which they framed in terms of the shortcomings of poor quality research. The first indicator is under-analysis through summary, which refers to occasions where 
researchers summarize the themes of what participants said, and fail to analyze the discourse within an interaction. The second indicator is under-analysis through taking sides, which refers to a researcher taking a position in relation to a speaker by aligning or not aligning with him. Ultimately, taking a side in analysis flattens the complexity of the interpretation of the interaction and is, in effect, not analysis. The third indicator is under-analysis through overquotation or isolated quotation, which refers to allowing the data to stand for itself without further comment. A hallmark of DP research is that the findings are presented with a line-by-line analysis of the selected, representative extract. Thus, only providing quotes with little or no detailed analysis is not viewed as reflecting a high quality study. The fourth proposed indicator is the circular discovery of (a) discourses and (b) mental constructs. This refers to the ostensible discovery of aspects of the interaction that are presupposed, as well as treating utterances as direct reflections of inner thoughts and feelings rather than interactional productions. This indicator points directly to DP's commitment to viewing mental constructs as interactional entities. The fifth indicator is under-analysis through false survey, which refers to treating the findings as reflective of all members of a given category in which the respondents are cast. The final indicator, under-analysis through spotting, refers to researchers simply spotting or noting particular conversational resources (e.g., pronoun use) at the expense of attending to how such conversational resources function to accomplish particular social actions. In other words, simply stating that a collection of conversational features exists entails little analysis and does not fully leverage the methodological and theoretical work central within DP research.

Beyond Antaki et al.'s (2003) indicators, we suggest there are (at least) six other considerations for ascertaining the quality of a DP study. First, as aforementioned, in DP the audio/video recordings are the data; therefore, the quality of the recordings is an essential aspect 
of quality in DP research. There are several potential challenges to ensuring a good quality recording. For example, there may be multiple voices and overlapping talk to capture, or a client may become upset, speak softly, or mumble, making it difficult to capture her words. Therefore, the placement of the recording device itself needs to be sensitively located as to not be obtrusive, but close enough to capture the encounter.

Second, the greater quality of the recording enables a more detailed and accurate transcription of the interaction using the Jefferson method (Jefferson, 2004). Notably, a DP researcher generally does not assume that there is 'hidden meaning' behind words and thus does not probe into the thoughts and feelings of the participant like researchers using other qualitative approaches might do. Rather, DP researchers often analyze naturally occurring social interaction. Therefore, it is crucial for the recording to capture the prosodic and paralinguistic features of the conversation, in order to include this information in the transcript. An important prerequisite for a successful analysis is careful attention to the details of the materials being studied (Potter, 2012). The more detailed the transcript, the better equipped the reader is to assess the quality of the analysis.

Third, consistent with its alignment with the analytic procedures of conversation analysis, a key element of DP is the consideration of how speakers orient to one another within an interaction (Potter, 2012). DP researchers assume that the meaning of any utterance can be better understood by attending to the preceding turn of talk and the subsequent utterance (Heritage, 1984). This close attention to the sequences of talk on a turn-by-turn basis provides a robust mechanism for checking that the analytic interpretations are truly grounded in the data (Pilnick et al., 2010), and are as close as possible to the utterances of the speakers (Edwards, 2012). 
Fourth, it is critical to identify and report deviant cases within the dataset. Attention to deviant cases assures that generalizations from the data are not made prematurely. Instead, these deviations allow a DP researcher to deepen her understanding of the phenomenon by continuing their analysis in search of deviant examples (Potter, 2012). Thus, a DP researcher should intentionally seek out alternative cases and explanations (Potter, 2004; Wood \& Kroger, 2000), attending to inconsistencies and diversity within the data set (Potter \& Wetherell, 1987).

Fifth, Potter and Wetherell (1987) suggested that the validity of findings is linked to the fruitfulness of the work and the researcher's ability to "generate novel explanations" (p. 171). Related to this, Tracy (1995) argued that fruitful discourse research creates "links between previously related issues," and raises "new questions" (p. 210). Practically, then, DP researchers typically report their findings in a way in which the connections between their claims and those of previous discourse-related research is evident to readers (Potter, 2012). For instance, if a DP researcher points to the use and social function of 'extreme case formulations' (e.g., expressions that use terms like 'all,' 'none,' 'every,' 'absolutely'), they would also provide references and make links to the body of literature that has already highlighted the various functions of such discursive resources. Thus, as DP researchers share their research findings, they aim to locate their work in relation to previously published discourse-related research.

Finally, the assessment of the quality of a piece of DP research extends beyond the analyst and includes the reader (i.e., reader evaluation; Potter, 2012). One of the key features of published DP research is that researchers aim to demonstrate their primary arguments by illustrating the steps involved in the analysis of a given excerpt of the data. Therefore, instead of telling a reader about a given interpretation and subsequently pointing to an excerpt that makes 
the researcher's point, the DP researcher shows how the extract was analyzed to arrive at the analytic claim (Wood \& Kroger, 2000).

\section{Recommendations for Future Counseling Psychology DP Researchers}

Learning how to do DP research requires a commitment to ongoing study. We provide several suggestions for where people new to DP may begin their study, including key readings and journals, university-based courses and workshops, and related professional organizations and gatherings.

The body of DP literature is robust and spans a range of disciplines. Beyond learning from published DP literature to gain familiarity with the foundations of DP, we recommend reading some of the original publications to gain an understanding of the core arguments that have served to delineate the theoretical and methodological practices of DP. First, Potter and Wetherell's (1987) book titled Discourse and Social Psychology, provides a historical context of the early perspectives around the relation between language and psychology. These perspectives continue to shape contemporary DP. This book also provides descriptions of interpretative repertoires and the general assumptions that undergird the earliest perspectives around DP. Thus, for researchers who may be interested in becoming more familiar with interpretative repertoires and researcher-generated data, such as interview or focus group data, this book is an important read.

Second, Edwards and Potter's (1992) book titled Discursive Psychology is required reading for those interested in doing DP research. This book was where DP, as a distinct approach, was first articulated. In this book, an overview of DAM is provided, serving to support scholars interested in applying DAM as an analytic framework. 
Third, Wiggins' (2017) book titled Discursive Psychology: Theory, Method and Applications, provides an easily accessible overview of the history of DP, and is one of the only books that provides a description of how to carry out a DP study. Wiggins' book also offers critical examples of DP research across multiple fields, including counseling psychology. Thus, this book is perhaps a useful starting point for those new to DP, as it offers a balanced discussion of both the underlying theoretical assumptions of DP and the methods required to carry out such a study. Beyond books, some of the key discourse journals include: Discourse Studies, Discourse \& Communication, Discourse \& Society, and Text \& Talk. These journals are interdisciplinary and thus publish research related to counseling psychology, and include studies that draw upon a variety of discourse analysis approaches, including DP.

Beyond becoming familiar with the literature, researchers interested in applying DP should aim to participate in academic and professional training opportunities. Understanding how to carry out a DP study requires engaging in analysis, which is best pursued with guided support and supervision. As previously noted, DP is less known in the United States; thus, perhaps unsurprisingly, relatively few academic institutions regularly offer DP-specific coursework. Nonetheless, there are a few exceptions, with some universities located in the United States offering graduate-level coursework related to DP (e.g., Indiana University). Beyond DP specific courses, conversation analysis coursework is likely far more accessible for most, as such coursework is more regularly offered in academic institutions across many geographic locations. Conversation analysis coursework is commonly offered in sociology programs and, at times, in schools of communication and schools of education. Given DP's growing focus on the sequential organization of interaction and, thus, its close methodological 
and analytical association with conversation analysis, participating in conversation analysis coursework is a fruitful endeavor and one that we strongly recommend.

Related to this, there are workshops and university sponsored seminars, most often related to conversation analysis, that provide specialized training and support. For instance, Rutgers' School of Communication and Information hosts two-to-three-day working seminars on conversation analysis. The National Communications Association, which has a Language and Social Interaction division, hosts an annual convention in the United States. This Division's programming regularly includes papers and symposia related to DP and conversation analysis, with many key DP scholars involved. The International Society of Conversation Analysis is another organization that regularly hosts conferences that bring together conversation analysis scholars, many of whom are trained in DP. This organization is multidisciplinary, with many members engaged in research related to counseling psychology. Its most recent conference took place in 2014 at the University of California, Los Angeles - the home of conversation analysis. This conference hosted 20 pre-conference workshops, which included training in Jefferson transcription. To stay abreast of the aforementioned training opportunities as well as new publications, we recommend regularly visiting the EMCA wiki (emcawiki.net).

\section{Conclusions}

In this article we presented DP, a qualitative approach that is well-established in European and Commonwealth countries, but remains largely unknown in counseling psychology in the United States. Compared to other qualitative approaches commonly used in counseling psychology (e.g., consensual qualitative research, grounded theory), DP's distinctive features include emphasizing the performative nature of language, naturally occurring data, and a finegrained analysis of talk. We also elucidated the relevance of DP to counseling psychology, 
provided recommendations for future DP counseling psychology research, and articulated why DP is a natural fit for counseling psychology research. We hope that DP will help open new strands of inquiry in counseling psychology research that offer alternative conceptualizations of taken-for-granted psychological constructs by spotlighting the value of naturally occurring, dayto-day human interactions and conversations. 


\section{References}

Antaki, C., Billing, M. G., Edwards, D., \& Potter, J. A. (2003). Discourse analysis means doing analysis: A critique of six analytic shortcomings. Discourse Analysis Online, 1. Available from: http://extra.shu.ac.uk/daol/articles/open/2002/002/antaki2002002 paper.html

Antaki, C., \& O’Reilly, M. (2014). Either/or questions in psychiatric assessments: the effect of the seriousness and order of the alternatives. Discourse Studies, 16(3), 327-345. doi: doi.org/10.1177/1461445613508898

Arribas-Ayloon, M., \& Walkerdine, V. (2008). Foucauldian discourse analysis. In C. Willig \& W. Stainton-Rogers (Eds.), The SAGE handbook of qualitative research in psychology (pp. 91-108). London, UK: Sage.

Auburn, T., Smart, C., Hanley Santos, G., Annison, J., \& Gilling, D. (2016). Discovering mental ill health: 'Problem solving' in an English magistrates court. In M. O'Reilly \& J. N. Lester (Eds.), The Palgrave handbook of adult mental health: Discourse and conversation studies (pp. 634-653). Basingstoke: Palgrave MacMillan.

Avdi, E., \& Georgaca, E. (2007). Discourse analysis and psychotherapy: A critical review. European Journal of Psychotherapy and Counselling, 9(2), 157-176. doi: $10.1080 / 13642530701363445$

Berger, P. L., \& Luckmann, T. (1967). The social construction of reality: A treatise on the sociology of knowledge. Garden City, NY: Anchor.

Burr, V. (1999). The extra-discursive in social constructionism. In D. Nightingale \& J. Cromby (Eds), Social constructionist psychology: A critical analysis of theory and practice (pp. 113-126). Buckingham: Open University Press. 
Clayman, S. (2002). Disagreements and third parties: Dilemmas of neutralism in panel news interviews. Journal of Pragmatics, 34, 1385-1401.

Combs, G., \& Freedman, J. (2012). Narrative, poststructuralism, and social justice: Current practices in narrative therapy. The Counseling Psychologist, 40, 1033-1060. doi: $10.1177 / 0011000012460662$

Conoley, C. W., Vasquez, E., Bello, B. D. C., Oromendia, M. F., \& Jeske, D. R. (2015). Celebrating the accomplishments of others: Mutual benefits of capitalization. The Counseling Psychologist, 43, 734-751. doi:10.1177/0011000015584066

DeJong, P., \& Berg, I. K. (2012). Interviewing for solutions. Belmont, CA: Brooks/Cole.

Edwards, D. (2012). Discursive and scientific psychology. British Journal of Social Psychology, 51, 425-435. doi: 10.1111/j.2044-8309.2012.02103.x

Edwards, D. (2003). Analyzing racial discourse: The discursive psychology of mind-world relationships. In H. V. D. Berg, M. Wetherell, \& H. Houtkoop-Steenstra (Eds.), Analyzing race talk: Multidisciplinary approaches to the interview (pp. 31-48). Cambridge, UK: Cambridge University Press.

Edwards, D. (2006). Facts, norms and dispositions: Practical uses of the modal verb would in police interrogations. Discourse Studies, 8(4), 475-501.

Edwards, D., \& Potter, J. (1992). Discursive psychology. London: SAGE.

Georgaca, E., \& Avdi, E. (2009). Evaluating the talking cure: The contribution of narrative, discourse, and conversation analysis to psychotherapy assessment. Qualitative Research in Psychology, 6, 233-247. doi: 10.1080/14780880802146896

Goffman, E. (1981). Forms of talk. Oxford: Basil Blackwell.

Hansen, J. C. (2005). Assessment of interests. In S. D. Brown \& R. W. Lent (Eds.), Career 
development and counseling: Putting theory and research to work (pp. 281-304). New York, NY: Wiley \& Sons.

Hays, P. A. (2016). Addressing cultural complexities in practice: Assessment, diagnosis, and therapy. Washington, DC: APA.

Hepburn, A., \& Jackson, C. (2009). Rethinking subjectivity: A discursive psychological approach to cognition and emotion. In D. Fox, I. Prilleltensky, \& S. Austin (Eds.), Critical psychology: An introduction (2 ${ }^{\text {nd }}$ ed., pp. 188-219). London, UK: Sage.

Heritage, J. (1984). A change-of-state token and aspects of its sequential placement. In P. Atkinson \& J. Heritage (Eds.), Structure of social action: Studies in conversation analysis (pp. 299-345). Cambridge, UK: Cambridge University Press.

Herk, N. A., \& Thompson, R. C. (2012). Strong Interest Inventory Manual Supplement. Retrieved from: https://www.psychometrics.com/wpcontent/uploads/2017/05/strong-manual-supplement-occupational-scales-2012.pdf

Hill, C. E. (2014). Helping skills: Facilitating exploration, insight, and action. Washington, DC: APA.

Hill, C. E., Thompson, B. J., \& Williams, E. N. (1997). A guide to conducting consensual qualitative research. The Counseling Psychologist, 25, 517-572.

Hill, C. E., Spiegel, S. B., Hoffman, M. A., Kivlighan Jr, D. M., \& Gelso, C. J. (2017). Therapist expertise in psychotherapy revisited. The Counseling Psychologist, 45, 7-53. doi: 1.o0r.g1/107.171/0770/101010100001061664411192

Jefferson, G. (1990). List-construction as a task and resource. In G. Psathas (Ed.), Interaction Competence: Studies in ethnomethodology and conversations analysis, number one (pp. 63-92). Maryland: University Press of America. 
Jefferson, G. (2004). Glossary of transcript symbols with an introduction. In G. H. Lerner (Ed.), Conversation analysis: Studies from the first generation (pp. 13-31). Amsterdam: John Benjamins.

Kiyimba, N., \& O'Reilly, M. (2016). The value of using discourse analysis to explore counseling and therapeutic interactions. In M. O’Reilly \& J. Lester (Eds.), The Palgrave handbook of adult mental health: Discourse and conversation studies (pp. 520-539). Basingstoke: Palgrave Macmillan.

Lester, J. N. (2011). Exploring the borders of cognitive and discursive psychology: A methodological reconceptualization of cognition and discourse. Journal of Cognitive Education and Psychology, 10(3), 280-293.

Lester, J. N. (2014). Negotiating the abnormality/normality binary: A discursive psychological approach to the study of therapeutic interactions and children with autism. Qualitative Psychology, 1(2), 178-193.

Lester, J. N., Karim, K., \& O’Reilly, M. (2014). “Autism itself actually isn’t a disability”: Negotiating a 'normal' versus 'abnormal' autistic identity. Communication \& Medicine, 11(2), 139-152.

Magyar-Moe, J. L., Owens, R. L., \& Scheel, M. J. (2015). Applications of positive psychology in counseling psychology: Current status and future directions. The Counseling Psychologist, 43, 494-507. doi: 10.1177/0011000015581001

O’Reilly, M. (2005). The complaining client and the troubled therapist: A discursive investigation of family therapy. Journal of Family Therapy 27, 371-393. doi: 10.1111/j.1467-6427.2005.0328.x

O’Reilly, M., \& Kiyimba, N. (2016). Academics are from Mars, practitioners are from Venus: 
Challenges of collaborative qualitative research partnerships with mental health professionals. Paper presented at 15th Annual Qualitative Methods Conference International Institute for Qualitative Methodology, May conference. Glasgow: UK.

O’Reilly, M., \& Lester, J. (2016). Building a case for good parenting in a family therapy systemic environment: Resisting blame and accounting for children's behaviour. Journal of Family Therapy, 38, 491-511. doi: 10.1111/1467-6427.12094

O’Reilly, M., \& Parker, N. (2014). "She needs a smack in the gob": Negotiating what is appropriate talk in front of children in family therapy. Journal of Family Therapy, 36(3), 287- 307. doi: 10.1111/j.1467-6427.2012.00595.x

Parker, N., \& O'Reilly, M. (2012). 'Gossiping' as a social action in family therapy: The pseudoabsence and pseudo-presence of children. Discourse Studies, 14(4), 1-19.

Pilnick, A., Hindmarsh, J. \& Gill, V. T. (2010). Beyond 'doctor and patient': Developments in the study of healthcare interactions. In A. Pilnick, J. Hindmarsh \& V. T. Gill (Eds.), Communication in healthcare settings: Policy, participation and new technologies (pp. 116). West Sussex: John Wiley and Sons.

Pomerantz, A. (1986). Extreme case formulations: A way of legitimising claims. Human Studies, 9, 219-229.

Potter, J. (1996). Discourse analysis and constructionist Approaches: Theoretical background. In J. T. E. Richardson (Ed.), Handbook of qualitative research methods for psychology and the social sciences (pp. 125-140). Leicester: The British Psychological Society.

Potter, J. (1997). Discourse analysis as a way of analyzing naturally-occurring talk. In D. Silverman (Ed.), Qualitative research: Theory, method and practice (pp. 144-160). London: Sage. 
Potter, J. (2002). Two kinds of natural. Discourse Studies, 4(4), 539-542.

Potter, J. (2003). Discursive psychology: Between method and paradigm. Discourse \& Society, 14(6), 783-794.

Potter, J. (2005). Making psychology relevant. Discourse \& Society, 16(5), 739-747.

Potter, J. (2012). Discourse analysis and discursive psychology. In H. Cooper (Ed.), APA handbook of research methods in psychology: Vol. 2. Quantitative, qualitative, neuropsychological, and biological (pp. 111-130). Washington: American Psychological Association Press.

Potter, J. \& Hepburn, A. (2005). Qualitative interviews in psychology: problems and possibilities. Qualitative Research in Psychology, 2, 1-27.

Potter, J., \& Hepburn, A. (2008). Discursive constructionism. In J. A. Holstein \& J. F. Gubrium (Eds.), Handbook of constructionist research (pp. 275-293). New York: Guildford.

Potter, J., \& Wetherell, M. (1987). Discourse and social psychology. London: Sage.

Quintana, S.M., Chew, A., \& Shell, G. (2012). Counseling psychology theory and research on race and ethnicity: Implications for a psychological science of diversity. In N. A. Fouad, J. A. Carter, \& L. M. Subich (Eds.), APA handbook of counseling psychology: Theories, research, and methods (pp. 453-489). Washington D.C.: APA.

Reynolds, J. (2013). The single woman: A discursive investigation. New York, NY: Routledge.

Ridley, C., \& Laird, V. (2015). The scientist-practitioner model in counseling psychology programs: A survey of training directors. Counselling Psychology Quarterly, 28, 235263. doi: $10.1080 / 09515070.2015 .1047440$

Sacks, H. (1987). 'You want to find out if anybody really does care'. In G. Button \& J. R. Lee 
(Eds.), Talk and social organization (pp. 219-225). Clevedon: Multilingual Matters Ltd.

Scheel, M. J., Berman, M., Friedlander, M. L., Conoley, C. W., Duan, C., \& Whiston, S. C. (2011). Whatever happened to counseling in counseling psychology? The Counseling Psychologist, 39, 673-692. doi: 10.1177/0011000010380278

Seligman, M. E., Steen, T. A., Park, N., \& Peterson, C. (2005). Positive psychology progress: Empirical validation of interventions. American Psychologist, 60, 410-421.

Slatcher, R. B., \& Pennebaker, J. W. (2006). How do I love thee? Let me count the words the social effects of expressive writing. Psychological Science, 17, 660-664.

Speer, S. (2002). Transcending the 'natural/contrived' distinction: a rejoinder to Ten Have, Lynch and Potter. Discourse Studies, 4(4), 543-548.

Stokoe, E. (2014). The conversation analytic role-play method (CARM): A method for training communication skills as an alternative to simulated role-play. Research on Language and Social Interaction, 47(3), 255-265. doi: 10.1080/08351813.2014.925663

Strauss, A., \& Corbin, J. (1998). Basics of qualitative research: Techniques and procedures for developing grounded theory. Thousand Oaks, CA: Sage.

Strawbridge, S. \& Woolfe, R. (2010). Counseling psychology: Origins, developments and challenges. In R. Woolfe, S. Strawbridge, B. Douglas \& W. Dryden (Eds.), Handbook of counseling psychology ( $3^{\text {rd }}$ ed., pp. 3-22). London: Sage.

Sue, D. W. (2013). Race talk: The psychology of racial dialogues. American Psychologist, 68, 663-672. doi: 10.1037/a0033681.

ten Have, P. (2002). Ontology or methodology? Comments on Speer's 'natural' and 'contrived' data: a sustainable distinction? Discourse Studies, 4(4), 527-530.

Tracy, K. (1995). Action-implicative discourse analysis. Journal of Language and Social 
Psychology, 14(1-2), 195-215.

Van Dijk, T (1993). Principles of critical discourse analysis. Discourse and Society, 4(2), 249283

Wampold, B. E. (2015). How important are the common factors in psychotherapy? An update. World Psychiatry, 14, 270-277. doi: 10.1002/wps.20238

Westefeld, J. S., Range, L. M., Rogers, J. R., Maples, M. R., Bromley, J. L., \& Alcorn, J. (2000). Suicide: An overview. The Counseling Psychologist, 28, 445-510. doi: $10.1177 / 0011000000284002$

Wetherell, M. (2001). Debates in discourse research. In M. Wetherell, S. Taylor, \& S. J., Yates (Eds.), Discourse theory and practice: A reader (pp. 380-399). London: Sage.

Wetherell, M. (2007). A step too far: Discursive psychology, linguistic ethnography and questions of identity. Journal of Sociolinguistics, 11(5), 661-681.

Wetherell, M., \& Edley, N. (2014). A discursive psychological framework for analyzing men and masculinities. Psychology of Men \& Masculinity, 15(4), 355-364.

Wetherell, M., \& Potter, J. (1992). Mapping the language of racism: Discourse and the legitimation of exploitation. London, UK: Harvester Wheatsheaf.

Wiggins, S. (2017). Discursive psychology: Theory, method and application. London: Sage.

Wong, Y. J. (2006). Strength-centered therapy: A social constructionist, virtues-based psychotherapy. Psychotherapy, 43, 133-146.

Wong, Y. J., Tsai, P.-C., Liu, T., Zhu, Q., \& Wei, M. (2014). Male Asian international students' perceived racial discrimination, masculine identity, and subjective masculinity stress: A moderated mediation model. Journal of Counseling Psychology, 61, 560-569. doi: http://dx.doi.org/10.1037/cou0000038 
Wood, L. A., \& Kroger, R. O. (2000). Doing discourse analysis: Methods for studying action in talk and text. Thousand Oaks, CA: Sage.

Woolfe, R. (1990). Counseling psychology in Britain: An idea whose time has come. The Psychologist, 3(12), 531-535.

Wooffitt, R. (2005). Conversation analysis and discourse analysis: A comparative and critical introduction. London: Sage.

Wooffitt, R. C. (1992). Telling tales of the unexpected: The organization of factual discourse. London: Harvester/Wheatsheaf.

Yin, R. K. (2016). Qualitative research from start to finish ( $2^{\text {nd }}$ ed.). New York, NY: Guilford Press. 
Appendix A: Jeffersonian symbols (Jefferson, 2004)

\begin{tabular}{|c|c|}
\hline Symbol & Meaning \\
\hline (.) & $\begin{array}{l}\text { A period inside parentheses denotes a micro- } \\
\text { pause; that is, a pause that is hearable but not } \\
\text { measurable or significant enough to measure. }\end{array}$ \\
\hline$(0.2)$ & $\begin{array}{l}\text { A number inside parentheses denotes the } \\
\text { length of a pause. }\end{array}$ \\
\hline ] & Square brackets denote overlapping speech. \\
\hline$><$ & $\begin{array}{l}\text { Text encased with 'greater than' and 'less } \\
\text { than' symbols denote a pace of speech that is } \\
\text { hearable as faster than the surrounding } \\
\text { speech. }\end{array}$ \\
\hline$<>$ & $\begin{array}{l}\text { Text encased with 'less than' and 'greater } \\
\text { than' symbols denote a pace of speech that is } \\
\text { hearable as slower than the surrounding } \\
\text { speech. }\end{array}$ \\
\hline$(\quad)$ & $\begin{array}{l}\text { A space between parentheses denotes that the } \\
\text { words spoken are unclear and therefore } \\
\text { impossible to transcribe. }\end{array}$ \\
\hline$((\quad))$ & $\begin{array}{l}\text { Double parentheses with an inserted } \\
\text { description provide contextual information } \\
\text { where no symbol of representation is } \\
\text { available. }\end{array}$ \\
\hline$\underline{\text { Under }}$ & $\begin{array}{l}\text { Underlining a word or a part of a word } \\
\text { denotes a rise in the volume or emphasis. }\end{array}$ \\
\hline$\uparrow$ & An upward arrow denotes a rise in intonation. \\
\hline$\downarrow$ & $\begin{array}{l}\text { A downward arrow denotes a drop in } \\
\text { intonation. }\end{array}$ \\
\hline$\longrightarrow$ & $\begin{array}{l}\text { An arrow denotes a particular sentence of } \\
\text { interest to the analyst. }\end{array}$ \\
\hline CAPITALS & $\begin{array}{l}\text { Capital letters denote that something was said } \\
\text { loudly or even shouted. }\end{array}$ \\
\hline Hum(h)our & A bracketed ' $h$ ' denotes laughter in the talk. \\
\hline$=$ & $\begin{array}{l}\text { An equal sign denotes latched speech; that is, } \\
\text { a continuation of talk. }\end{array}$ \\
\hline$\because::$ & $\begin{array}{l}\text { Colons denote elongated speech; that is, a } \\
\text { stretched sound. }\end{array}$ \\
\hline
\end{tabular}


Figure 1. The Process of Carrying Out a DP Study.

- Obtain data access and participant consent.

-Data is often naturally occurring.

- Make sampling decisions.

- Manage data.

$3 \quad$ Create an audit trail.

- Transcribe data using Jefferson method of transcription.

- Redevelop the research questions.

- Build a corpus of examples that demonstrates an identified phenomenon.

- Check the quality of analytic claims and of the overall study. 